JOURNAL OF ENGLISH STUDIES, II (2000), 61-78

\title{
NEW DIRECTIONS OR THE END OF THE ROAD? WOMEN'S TRAVEL WRITING AT THE MILLENNIUM
}

\author{
Maureen Mulligan \\ Universidad de Las Palmas de Gran Canaria
}

\begin{abstract}
Women's travel writing in the twentieth century can be seen as an area of new literature which both absorbs earlier styles of both male and female travel writing, while developing in the direction of certain discourses which have found strong ideological support in social and literary concerns at the end of the century. The key discursive trends in post-colonial women's travel writing can be defined as those of feminism, (anti)-tourism, 'tough' travel, post-colonial awareness, and concern for certain environmental issues. In this paper we will consider how these trends are reflected or challenged in some recent examples of women's travel writing. The texts referred to here offer a range of positions and concerns which in some ways suggest the limits and possibilities of contemporary travel writing. Without wishing to reduce the books discussed to a single interpretative position, it may be helpful to highlight two differing approaches to the continuing problem of how to write about the Other and how to represent oneself and one's own culture in the process. Desert Places by Robyn Davidson (1996) is considered in terms of its author's loss of conviction in the travel writing project; and Terra Incognita by Sara Wheeler (1996) in terms of travel as an interior, imaginative venture into a landscape of myth and emptiness.
\end{abstract}

Women's travel writing in the twentieth century can be seen as an area of new literature which both absorbs earlier styles of both male and female travel writing, while developing in the direction of certain discourses which have found strong ideological support in social and literary concerns at the end of the century. The key discursive trends in post-colonial women's travel writing can be defined as those of feminism, 
(anti)-tourism, 'tough' travel, post-colonial awareness, and concern for certain environmental issues. In this paper we will consider how these trends are reflected or challenged in some recent examples of women's travel writing. The texts referred to here offer a range of positions and concerns which in some ways suggest the limits and possibilities of contemporary travel writing. Without wishing to reduce the books discussed to a single interpretative position, it may be helpful to highlight two differing approaches to the continuing problem of how to write about the Other and how to represent oneself and one's own culture in the process.

Desert Places by Robyn Davidson (first published, 1996) is considered in terms of its author's loss of conviction in the travel writing project; and Terra Incognita by Sara Wheeler (first published, 1996) in terms of travel as an interior, imaginative venture into a landscape of myth and emptiness. Both these texts will be discussed from the point of view of motivation for travel, choice of destination, aims and achievements on the part of the author, and relationship with the people among whom the writer travels. The rhetorical presentation of the first person narrator will also be an important aspect of this analysis. Finally, an understanding of travel writing as a series of re-writings and interconnecting discursive codes will enable us to read other travel texts in the context of a literary tradition which is still learning from its ancestors and redefining its contemporary codes through the interplay between individual writer / traveller and the intertextual nature of all written discourses.

Desert Places by Robyn Davidson (1997) recounts the experiences of the author, an Australian who lives in Britain, when she travelled with a group of nomads known variously as the Rabari or the Raiki in northern India. Initially the project follows the pattern of much women's travel writing in the post-colonial period: the writer signs a contract to provide articles for a magazine in return for financial support; she is allocated a professional photographer; she knows little about where she is going because she has deliberately chosen a tribe and an area which is almost undocumented, and by its very nature as nomadic, cannot be pinned down. Despite the lack of information available, she is inspired to travel with them because of the avowedly romantic image evoked in her by the idea of the nomadic life:

A wish was forming. It took the shape of an image. I was building a little cooking fire in the shelter of soft, pink dunes, far away from anything but a world of sand. It was twilight, the lyrical hour. The nomads were gathering beside me by the fire. There was fluency and lightness between us. We had walked a long way together. The image exalted the spirit with its spareness and its repose (Davidson 1997: 3). 
She does not speak any useful languages and has no experience of tribal nomadic life. Thus far her journey resembles many others, going back to that undertaken by Mary Kingsley (1993) in her desire to enter the life of a completely alien and unknown social system alone, and reminding us of journeys by Ella Maillart (1986), Alexandra DavidNeel (1988) and Isabella Bird (1982) in the way she is searching for a people who offer a more primitive and therefore supposedly more 'genuine' or 'authentic' alternative lifestyle. Her romantic view of desert life as an escape from twentieth century civilisation echoes the enchantment felt by Gertrude Bell (1907) and the young Freya Stark in Iraq (1938). However, despite conforming to the general tradition of destination and style of journey identified as common to the twentieth century travel writer, Desert Places is not simply another account of the Western woman's intrepid spirit triumphing over hardship and cultural difference to reaffirm the bonds between herself and her thirdworld sisters. Although these ideas are there in the first part of the book, in fact the journey turns out to be a personal nightmare and an admitted failure in terms of her aim of studying the Raika. There is a three year gap between the end of the journey (which, with various false starts, seems to have lasted about a year) and the writing up of the account:

For a long time I could not see how to write about my experiences. They were nothing but a series of disconnected events, without shape, without meaning. I had passed through India as a knife does through ice and it had closed behind me at every step. How does one write about failure? (Davidson, 1997: 275).

Part of the problem, both with the journey itself and with the form of travel writing attempted, is caused by Davidson's tendency to romanticise the nomadic Other, when the reality she experiences is anything other than romantic. For her, the Rabari represent a return to a more authentic past which was lost with the advent of agriculturalism; the nomads are a special people who embody an alternative path for mankind which echoes in our collective memory. She writes "Rabaris were the keepers of the original way nomadism" (ibid: 57); "This century [...] is witnessing the end of traditional nomadism, a description of reality that has been with us since our beginnings - our oldest memory of being" (5); "Their history began in Jaisalmer in the Thar Desert, from which over the centuries they had spread with their animals into other states, splintering into other subcastes but retaining, always, their 'Rabariness', their otherness" (12). Here she even uses the key term of structural difference, 'otherness', reminding us of its use in work by Edward Said in Orientalism to signify the Western way of representing the East. As a people without a homeland, even within the social structure of the East the Rabari remain Other. To the Western reader or traveller, they are thus doubly 'othered', and as such an object of anthropological and historical interest. 
At the same time, Davidson chooses to identify herself with this romanticised nomadic tradition because she has (voluntarily) moved between various First World countries and no longer feels particularly identified with any of them; she represents herself as a modern nomad:

There are new kinds of nomads, not people who are at home everywhere, but who are at home nowhere. I was one of them. After the first abandonment of the place of my birth I had lived in England, in America, lost count of the countries I had visited and had several times returned to Australia only to leave again. Somewhere in the midst of that tremendous restlessness I had lost the sense of a gravitational centre, a place with which to compare elsewhere. I now felt as much an anthropologist (mystified, alien, lonely) at a dinner party with my peers, as I did with a family of Aborigines eating witchetty grubs in a creek bed (Davidson 1997:5).

Thus the author situates herself as a person without cultural identity who has more in common with simple native peoples existing in unadulterated natural conditions, than she has with her Western peers. She actively desires identification with the nomad tribe before she has even met them, and is keen to reject the life of 'civilisation' she has access to in the West. But as Amit Chaudhuri (1997: pp.19-20) writes in his review of Desert Places:

Time and again, Davidson, in her account of her life with the Rabari, returns to the subject of herself. There is nothing intrinsically wrong in this: the problem is that Davidson, like so many Western travel writers, relinquishes the specificity, the particularity, of her own - Australian- background and identity for the archetypal persona of the 'Western' visitor to India. Does an unequivocal, homogeneous entity called the 'West' really exist?

The focus of the book is suggested in the quotation from Robert Frost's poem of the same name which identifies the 'desert places' as interior, existential states, not foreign landscapes. But apart from her ultimate frustration with her companions, we learn little about Davidson's interior journey and less about the minds of the Rabari. Amit Chaudhuri points out the fundamental flaw in the project:

It is not difficult to imagine what it would be like for a middle-class Australian woman were she to find herself for days on end with a group of nomads; and there is very little in the book to subvert our expectations. It is more difficult, perhaps, to imagine what it is to be a Rabari, sleeping among five thousand sheep and drinking Guinea-worm-infested water; but Davidson, constrained by her ignorance of their language, and their ignorance of hers, offers few insights on this subject. From time to time she laments that her journey has 
provided her with no 'illumination'; yet it is not illumination one seeks in this account, but something more humble, a small-scale but sustained going-out-ofoneself into other people's lives. To me, the idea that living in the most trying conditions with a group of strangers, and getting infected with the same diseases and sores as they have, will lead to a greater knowledge of oneself, or others, or a culture is simply wrong-headed. (Chaudhuri 1997: 20)

This is a fundamental critique of the travel writing project as undertaken by Davidson (and others). In trying to cover in a single book the metaphysical ground of the interior existential journey, at the same time as dealing with the socially and politically correct agenda of feminism, environmentalism and 'World-culturism', the danger is that the writer falls between the two and fails to provide either an insight into how the alien culture affects her self-definition, or an objective account of how the alien culture constructs the world.

One of the main themes throughout the book is Davidson's attempt to find acceptance within a 'family', to become an insider, to be, as she puts it, "allow[ed] inside the frame" (Davidson 1997: 279). Describing the sight of some of the Rabari women at the well, while she herself tries to hide from the endless intrusive stares and hostility she elicits wherever she goes, Davidson writes:

I imagined going with them to the shop to haggle over the price of grain, felt the physicality of the heavy pot, the intimacy of a sister's arm around the shoulder, of gossip. I had imagined that I could become, over time, an element within the picture rather than an observer peering in. But it seemed more likely that I would never find myself there, inside the frame (Davidson, 1997: 46).

The idea of 'sisterhood' occurs repeatedly, resonating as it does in the anthropological discourse of family structure as well as in a feminist or woman-centred discourse. References to physical contact between women are frequent, as are comments about the writer's appearance, clothes and hair, and how these are seen by the local women. Without any language to communicate, the strength of international sisterhood initially enables Davidson to overcome cultural divisions by having her eyes made up with kohl by a Rabari woman: "We managed to communicate about the important things - clothes and make-up. Did I happen to have any nail-polish with me?” (108). Elsewhere: "Everyone got down to serious female politicking, or, as it is fallaciously known, gossip" (116). The effect is a deliberate challenge to male discourse in travel writing in which it is supposed such 'girly' and trivial issues are not discussed. In terms of tradition it reminds us of Freya Stark getting access to Iraqi princesses in the harem which would be denied to male travellers. In terms of locating the discourse of the text in the postfeminist culture of the intended readership, the device may be effective; however, the 
actual relationships developed with the women she meets hardly move beyond bemused incomprehension on both sides, breaking at times into direct hostility on the part of the Rabari women towards someone who spends months with a small group and is unable to learn even their names:

They had welcomed me into the warmth of their communion; now I was out in the cold watching them through a window. They would see me peeping at them and turn away as if to say, Why are you looking at us? Go away! What had begun with good will was atrophying for the want of a language to nourish it. I had imagined I could understand, through a kind of pre-lingual sign language, quite complex interactions, as if I could just manage to stay afloat on an ocean of incomprehension. The truth was I was going under. There were more than forty people on the dang. Jaiva said disparagingly, 'We can remember all our sheep. How come you can't remember our names?' (Davidson 1997: 134).

Almost all the emotionally charged epiphanic moments which punctuate a text otherwise full of negative experiences, culminating in a kind of insane hysteria towards India and Indians, are to do with Davidson's temporary sense of belonging to a family, though we are also aware that this is a privilege she pays for in rupees:

At last the price was fixed - two thousand rupees a month. I must provide my own food and buy my goat milk from them. They would provide camel, saddle and gear. Narendra proclaimed, 'From now on Pala bhai's family is your family', and everyone stood up and shook hands and ordered tea in celebration. (Davidson 1997: 92)

However the reality of 'family' life with the Rabari leads to the darker side of this theme developing as an obsession with her loneliness, boredom and gradual recognition that she is an outsider who is only accepted in so far as she proves useful to the tribe. The jeep she has bought and hardly uses is her greatest asset in the eyes of the exhausted Rabari, who cannot understand why anyone would choose to walk when they could ride:

I drove the women into the nearby village for provisions, which completely turned their heads. On the way back my sisters sat in the front with me, heaping scorn on mere pedestrians. Parma, thinking I couldn't understand her, announced, 'This is our taxi and Ratti ben [Davidson] is our driver' (Davidson 1997: 148).

Davidson resents the way her jeep is used for tribal business when Phagu, the leader, uses it to save time scouting the land ahead, and she interprets their behaviour, on one of the few occasions on which she inadvertently contributes something useful to the longsuffering Rabari tribe, as a clever trick to exploit her: 
It was not the recce I resented, it was his manipulation of me [...] By the time we got back it was dark. The whole community welcomed me home with prashad and high praise but I was too fed up with them to be conned out of my mood and went straight to my tent. In my notes I wrote 'I am their milking cow' (Davidson 1997: 163).

Davidson is offended that they are too ready to reject their traditional ways and 'exploit' her as a free taxi-service, when she wants them to offer her the 'genuine' nomadic experience (as long as she can get off the camel and into a jeep whenever the reality of poverty becomes too painful or boring). She shows apparently no awareness of how the whole tribe's efforts in putting up with and looking after a completely useless extra body who cannot communicate or make chapatis or load her own camel or wash her nether regions without offending people, perhaps deserve to be rewarded with something more than the chance to appear as photo-opportunities in a book they will never read.

The solitariness of Western life, the alienation of cities, the breakdown of the family: these are the classic tropes motivating romantic travel writing, often juxtaposed with the glorification of the close physical and relational solidarity evident in poorer societies whose members stick together in ways that have been forgotten in the consumerist, divisive West. Annette Kobak (1997:35) argues in a review of Desert Places that the book fits into a tradition of 'elegiac' travellers who feel the West turns to primitive cultures in a search for lost roots, and for women, lost freedoms:

Like many elegiac travelers (Norman Lewis, Wilfred Thesiger, Bruce Chatwin), Ms. Davidson feels that humans lost something when they abandoned the ancient nomadic life. Women particularly lost out, she thinks, observing that nomads breed far less than, for example, women in purdah, who are permanently confined in both senses. Nomadism leads, she feels, to a better balance of power between the sexes among the Rabari [...] The book is an X-ray of what the industrial West has lost and, in equal measure, why we wanted to lose it.

Yet Davidson discovers the hard way that such solidarity among the poor and dispossessed cannot be bought or created during a short trip; on the contrary, it only serves as a contrast with her own lack of identity and direction. Her doubts about the value of the journey are a recurrent leitmotiv in the text:

But was it really useful, I asked myself, to travel with a bunch of nomads no one has ever heard of? So what if the Rabari will be extinct within fifty years? Who in the world will give a damn? [...] And so what if nomadism was about to go out, phut, like a candle, the whole world over? The culture of the millennium had bigger things to worry about. But I'd committed myself and there was no turning back (Kobak 1997: 35). 
If Davidson herself questions her motives, the Rabari are completely bemused by what seems to them complete insanity:

Men would come and sit with me, polite as ever, and gradually get round to asking, 'You have lakhs and lakhs of rupees, and you have a jeep. Why do you want to live with poor people? Why do you want to walk?' I never found a suitable reply to this but it did indicate how far from enviable they saw their own lives and how incomprehensible they found mine (Davidson 1997: 48).

The very meaningless of the trip is used as a justification for continuing what has become not only an artificial but also a masochistic exercise: "There was a deeper motive for the prolonging of self-punishment: the quest for meaning, of which, so far, this curious journey had remained void" (182). However, even Davidson's masochism has its limits, and when life with the Rabari gets too unbearable, she (unlike her 'family') has several escape routes. One is her deep grounding in a romantic view of the Third World, which she uses to revive her spirits by equating poverty with 'inner freedom':

That old sunset and dune picture, which I had thought long lost, was still there - blotched, faded and curling at the edges, but romantic still. In my imagination I saw a country road winding through granite hills or threading the sides of dunes [...] people on bicycles or bullock carts came along [...] With this image went a sense of inner freedom, a kind of expansiveness in the chest as if a tight band had been loosened. I would be able to 'see' at last what was around me, able to engage with it. I would be allowed 'in'. I would find some way of camouflaging myself (Davidson 1997: 182).

Colonialism has left a heritage that the white female visitor to India cannot ignore, yet evidently feels uncomfortable with - though it does not stop her exploiting its benefits when convenient: Davidson makes a joke about being referred to as 'Memsahib' by her various servants, but accepts the role of mistress; she resents being stared at for her whiteness, but accepts the privileges of queue-jumping in doctors' waiting rooms and access to exclusive hotels. There is even a 'Livingstone / Stanley' joke, as though she were an explorer.

Following the agenda set by the photographer as to what is worth researching, the text includes occasional forays into watered-down anthropological description of those aspects of Indian life most appealing or shocking to Western readers: child marriages, mythical histories of the Rabari involving animal gods, women and betrothals, religion and the routines of pastoral life. But we have to remember that the information provided has been filtered through a 'contact' whose linguistic skills preclude any normal conversation. This deficiency considerably reduces the value of the information she presents, which is in any case minimal and anecdotal: the vast bulk of the text focuses 
on her sufferings and deprivations at the hands of the "inconsiderate" Indians she is forced to deal with. There is little room left for an objective study of their lives and concerns.

In an interview with Robyn Davidson on Australian radio, the author focuses on an epiphanic moment in her trip when the apparently beautiful, picture-postcard image of the nomadic life is contrasted with her awareness of the image's falsity:

Of course, what I know by that point is the truth of that picture which is that the little Rabari men are starving and the ribbon of water is full of malarial parasites and the Aravali Mountains are being deforested and there is junk in the streams and there are hideous, kitsch hotels where middle-class people can stay and not see. (ABC Charting Australia 108, broadcast 28 April 1996)

This makes good postmodern, pro-green, minority-culture journalism, but it is difficult not to agree with Annette Kobak's comment (1997: 36) that the book "does not quite escape an aura of bad faith" when we realise that Davidson herself was only too happy to stay in such hotels, and that her own participation in the culture of consumerism and environmental destruction is embodied in her purchase of an unnecessary jeep.

In classic orientalist discursive tradition, Davidson presents the Rabari as not only geographically and culturally alien to Western culture, but also temporally alien through references to the Arabian Nights; to Sinbad; to parts of India that "would have looked just like this centuries ago" (13); "I was a tourist in pre-industrial time" (162); "I would be - had already been, without realizing it - a traveller in medieval time" (237). This is, of course, one of the most obvious tropes of orientalist thinking identified by Said as a way of fixing the East permanently in the past, in opposition to Western modernity, progress etc. Despite Davidson's romantic view of the timelessness and picturesqueness of nomadic life, she finds that the Rabari would be only too happy to move into the twentieth century and enjoy some of its comforts, and are only barred from doing so by their extreme poverty. Equally, the reality of twentieth century 'development' impinges on their lives in a way she had not anticipated, affecting nomadic routes and customs. (The appearance of Davidson herself in the tribe is an example of the Western impact she would prefer them to avoid). The clash of expectations on the part of Davidson and her tribal hosts is at times unconsciously funny; she cannot believe the women will take the bus rather than walk to Pushkar, and they cannot believe that anyone would walk if there is an alternative (25).

The book is structured around these contradictions, and it is to the author's credit that her honest doubts about the nature and value of her project eventually come to be foregrounded in the text. However the extreme level of anger, complaint, insult, frustration and unhappiness revealed in the detailed account of the journey raises 
difficult questions about the role of travel writing not just in the case of this book but in general, given the specific situation of the Western traveller in the world at the end of the twentieth century.

The nihilism of the book suggests we have reached the point at which any form of travel into a third-world country, however much the author wraps it up in terms of pseudo-anthropology, pseudo-international sisterhood or pseudo-environmental concern, is getting too close to an unjustifiable mixture of cheap tourism, voyeurism, exploitation and game-playing in the face of other people's poverty and misery. Kobak (1997: 36) writes, “The whole very western enterprise of a lone traveler alighting amid some remote group of people and making a living by writing about them is getting ethically trickier". In the last chapter before the Coda, Davidson describes her anger (both with herself and with the whole of India) thus:

The anger chewed me up. I could not sleep at night with it. There was nowhere to dump it. Everything I had done here was fraudulent and absurd. I knew nothing about the Rabaris and, even if I did, it would mean nothing to them, make no difference to them. I had understood nothing of where I was. And I would perpetuate the fraudulence by producing yet another bit of noise for a culture drowning in noise - an article for a glossy magazine with beautiful photos of beautiful India, beautiful noble Rabari, so that people could sit in comfort in their homes or doctors' waiting-rooms and not see (Davidson 1997: 272).

Yet despite this insight the demands of the career travel writer triumph: it is true that the colour photographs are included in the paperback edition, and give it precisely the feel of a National Geographic article rather than an individual's experience of travel; they contrast remarkably with the bitterness and realism of the text. Davidson realises the journey "is reduced to kitsch" (273) because by the end she is commuting between the first and third worlds as she stays in air-conditioned hotels and is driven to the Rabari in her jeep for photo-shoots that provide a "visual reconstruction" (263) of the proposed walk.

The journey fails on many levels: personally, she cannot bear to be with her camel driver Chutra whom she refers to as a "bastard", "arsehole", "idiot", etc. She discovers that the tribes do not migrate in the old sense, with whole picturesque villages of happy, wild nomads following their flocks across romantic deserts, but tend to take the bus where possible, and often leave the women behind. The route she finally follows forces her to abandon her original romantic image:

In locating a group of Raika I always took into account such things as desert vistas, pretty jhumpas, dramatic photos of arrivals in Pushkar - that sort of thing. Bhairon's people, I knew, lived in boring, eaten-out farmland, and would take their animals along the Chambal river beside factories, sewerage outlets and leaky 
nuclear power stations, and on into the dacoit-infested badlands. Not exactly the sunset sand-dune descriptions with which I had secured the magazine's interest and cash (Davidson 1997: 67).

Instead of considering the implications of such poverty and destruction on a social and environmental level for the Indians who have to suffer these consequences of thirdworld 'development' (itself part of the same Western capitalist system which is paying for her trip) the only interpretation offered is a complaint that her photo-opportunities are not classic tourist images. Kobak highlights these contradictions pointing out that while Davidson takes it on herself to "ask belligerent questions about corruption in the community and puts under scrutiny the evasions that allow her hosts to get by", her own moral high ground is increasingly suspect: "Yet she doesn't feel obliged to lay bare with equal candor her own economics: how much she gets paid by her publishers and how much of that goes to the Rabari. It is the particular puritanism of the genre to stop not at the bedroom but at the airplane door" (Kobak 1997: 36.).

Davidson hides behind the myth of India as the ultimate spiritual cleanser, the desire for self-annihilation in the face of timeless nature, travel as escape from reality - we are back in the discourse of romantic, orientalist constructions of the 'mysterious East', in which the reality of the experience, however negative, must not be allowed to override the perpetuation of the myth of the Other. The transcendental 'moments' sketched by Davidson as a riposte to her growing doubts are the necessary poetic mythologising of a professional writer who cannot admit that she has reached the end of the road.

The quotation from Thomas Pynchon's novel $V$ with which Sara Wheeler prefaces Terra Incognita: Travels in Antarctica, "You wait. Everyone has an Antarctic"”, is one point of connection between this text and Robyn Davidson's Desert Places, which as we have seen, takes its name from a poem by Robert Frost: "They cannot scare me with their empty spaces / Between stars - on stars where no human race is. /I have it in me so much nearer home /To scare myself with my own desert places." (in Davidson 1997: i.)

To both women, writing in the 1990s, their choice of destination represents a deliberate exteriorisation of a state of mind as much as an actual geographical place. In the increasingly post-modern, postcolonial, global-village world of late twentieth century travel writing, this focus on travel as a metaphor for the subjective journey of the human spirit, rather than as an objective, descriptive, guide-book-style investigation into an unknown culture, is an inevitable development. Travel writing has to justify its existence in the face of scientific and anthropological approaches, television documentaries, even accounts of life outside the metropolis by the 'natives' themselves, some of whom now have academic research grants and publishing power from which to "write back" to the former empire. We have moved from Marlow's "blank spaces on the 
map" to the claim by Sara Wheeler and Dea Birkett (1998: viii) in their anthology Amazonian: The Penguin Book of Women's New Travel Writing that "there are no longer any empty spaces on the map".

The coincidence in the choice of metaphorical focus of the travel accounts by Davidson and Wheeler goes further: not only is the journey about the writer's psyche rather than about the landscape and people encountered, but both choose to undertake trips to hostile, apparently inhospitable regions which they visualise as embodying pristine emptiness ( in fact in neither case is this so). The Northern Indian desert and the snowy wastes of Antarctica are both connected and opposed as metaphors, but both emphasise the extremes of an environment as far from the comfort of Western civilisation as possible, in which the traveller is thrown back on her own mental resources to survive the isolation and the strangeness of the journey. Wheeler comments that in her initial research into Antarctica, based mainly on its literary and cinematic treatment, she saw that

Antarctica existed most vividly in the mind. It was a metaphorical landscape, and in an increasingly grubby world it had been romanticised to fulfil a human need for sanctuary. Mythical for centuries, so it remained (Wheeler 1997: 3).

If the rationale for the journey is to provide an appropriate symbolic setting for the inner landscape and interior adventures of the individual writer's personal odyssey, then perhaps it makes sense to choose a destination whose overriding feature is emptiness. It is then up to the writer to fill that emptiness with the literary re-creation of the distance travelled psychologically. Robyn Davidson's version of this in Desert Places becomes a kind of sense-deprivation chamber, in which her frustration at having deprived herself of the ability to communicate curdles into paranoia and hatred of the people she chose to travel with. Sara Wheeler avoids this danger partly because Antarctica has no indigenous population: the people she has to deal with, mainly male scientists (referred to metonymically as 'beards') and workers on the research stations, are both objects of her humour and sources of assistance and friendship. No-one alive is given much of a role in her portrayal: even the man with whom she has a brief affair and the artist with whom she shares an isolated camp are thinly-sketched caricatures. Her real interest in the human aspect of Antarctica lies with the past heroes, the mythical explorers of what she calls the "Heroic Age": Scott, Shackleton, Nansen, even Captain Cook. The key to Wheeler's construction of the Antarctic lies in what Apsley Cherry-Garrard, one of Captain Scott's men on an expedition south in 1911, describes as "the response of the spirit". Within the history of exploration, Antarctica holds a special place as the last of

1. Joseph Conrad, Heart of Darkness, 1898/1973: p.8. 
the blank spaces to be explored, and within the British tradition of martyred heroism, Scott's silver medal to Amundsen's gold is the archetype of the tragic failure which is subsequently converted into success by the myth. It is in this sense that the 'response of the spirit' is crucial: the British party may have failed to reach the Pole first and died on the return journey, but they died heroically, and this heroism was largely created through Scott's letters and diary. Wheeler uses the myth of Scott and his men as a way of filling the emptiness of the Antarctic with the history of a Golden epoch, while recognising that this very myth is a literary creation, a work of the imagination: this is the centre of her own exploration of the meaning of the South Pole:

Through his writings, Scott elevated the nature of the struggle. It was no longer man against nature, it was man against himself. The diaries reveal a sense of apotheosis: the terrible journey back from the Pole was a moral drama about the attainment of self-knowledge. Scott went to the mountaintop, there on the blanched wasteland [...] Defeat on this earthly plane was transfigured. The journey becomes a quest for self-fulfilment, and Scott's triumph is presented as the conquering of the self (Wheeler 1997: 52).

Thus we return to the interest in the self as the true material for twentieth century travel writing. It is understandable; it is also convenient as it fits into popular concerns promoted by feminism and post-colonialism. Wheeler and Birkett, in their introduction to Amazonian, place this focus at the centre of what they hope to promote as New Travel Writing:

The writer's inner journey is the most important part - and certainly the most interesting part - of any travel book. It doesn't make any difference where you go; it's your interpretation of it that matters [...] Now that writers have been everywhere, this feature - the inward-looking eye - is more important than ever. More important than anything else. The journeys writers make are slip roads to the private colonies of the imagination [...] It is the psychological journey that is paramount. 'The most foreign country', Alice Walker wrote, 'is within" (Birkett and Wheeler, 1998: ix).

But inevitably, if this is the case, then the travel book stands or falls on the quality of the mind of the writer being explored; and the old image of the 'armchair traveller' becomes obsolete as we can no longer turn to travel writing to inform us about parts of the world we cannot all visit. As Nicola Walker (1998: 27) puts it in a review of Amazonian: "But isn't it just as important that the reader learns about wherever it is that the writer has chosen to go?" She points out that "redrawing the boundaries of travel writing" as the book's blurb claims actually means little more than "co-opting, among some astute descriptions of place, the kind of personal detail and introspection that have 
traditionally belonged in autobiography and fiction." We should also remember that the presumed boundaries referred to are actually far more complex and flexible than the editors of the "New" travel writing wish to admit. As we have seen in travel writing throughout the last century, there is a strong tradition of mixing fiction, autobiography, philosophical reflection and spiritual enquiry, with descriptions of journeys undertaken. Each individual author works within a rhetorical and discursive field allowing them to place themselves on the continuum between travel-writing-as-guidebook and travelwriting-as-poetic-fiction.

Many of the discursive concerns we have found in earlier travel writing can be identified in Wheeler's rhetoric in Terra Incognita. These in turn are structured around contrasts and oppositions that are also familiar: silent, unspoilt, pristine nature contrasted with dirty, noisy, depressing city life; the romance and escape of travel contrasted with the 'real world' of humdrum daily home existence; the saintly, martyred Heroic Age of travel exploration contrasted with the professional pragmatism of scientific research or the trivial hedonism of tourism; imperialism and nationalism contrasted with a kind of ideal postcolonial supra-national sharing of an unowned wilderness; and the millennium sense of first and last - the last great journey on earth, the first person to see the landscape. There is also the inevitable opposition between men and women; between science and art; the relationship to the country is represented as an unrequited loveaffair; the journey is a quest for a spiritual goal, not for material gain.

One aspect of the rhetoric that is not so common in travel accounts is Wheeler's use of literary and cultural referents (books, poems, art, music) to fill out the white expanse of emptiness: the book contains over seventy bibliographical references, ranging from poetry to science to history to fiction, as well as reference to detailed research of unpublished material such as letters and diaries belonging to past explorers. The very fact of Antarctica being a vast empty space means that all meaning invested in it during the century in which humans have explored it comes from written, constructed, rhetorical accounts of personal struggles, rather than events or sightings of natural phenomena or descriptions of societies and cultures. Antarctica offers the writer an earthly space outside the normal world, and for Sara Wheeler the way to fill this space is through the imagination.

She refers to the imagination directly at least thirteen times in the book, and "the response of the spirit" is used as a synonym for this Coleridgean concept. Incidentally, Coleridge himself is discussed in some detail; in writing The Rime of the Ancient Mariner, Wheeler points out that he had never been abroad, but "saw the ice with his inner eye" (219) in the same way as she comments on George Eliot's ability to hear the famous 'roar which lies on the other side of silence': "She had never been south, of course. She didn't need to go" (67). Travel is seen almost as a superfluity, necessary only 
for those who lack the imagination to create their own inner journeys. The chapter with the title "The Response of the Spirit" is placed at the centre of the book, and this idea is more clearly foregrounded in the text than any other - certainly more than descriptions of penguins, cold or snow.

Antarctica was my love-affair, and in the south I learnt another way of looking at the world. What I want to do now is take you there. As Shackleton says, 'We all have our own White South', and I believe that the reach of the imagination extends far beyond the snowfields (Wheeler 1997: 8).

And similarly, among many examples:

I heard the still small voice. I had never known certainty like it. I felt certain that a higher power exists, and every soul constitutes part of a harmonious universe, and that the human imagination can raise itself beyond poverty, social condemnation and the crushing inevitability of death (Wheeler 1997: 94).

Her choice of destination has respectable ancestry in Alexandra David-Neel's literary celebration of the idea of global mobility in My Journey to Lhasa, of the irrelevance of national boundaries and concepts of ownership of land: David-Neel travelled to Tibet in 1927 precisely because it was forbidden; Wheeler chooses Antarctica because it seems forbidden to any but male scientists and explorers and because it is not owned or colonised by a single nation ("Geopolitics dwelt in the north; on the ice there was only one enemy - the cold”: Wheeler 1997: 243). The lack of an indigenous population in Antarctica means the only cultural problem she has to deal with is a largely male-dominated scientific culture. As Lucretia Stewart (1996: 41) writes in a review of Terra Incognita:

Seen through Wheeler's eyes, the Antarctic comes across as one huge research camp, in which everyone is a scientist or a researcher of some kind, including, however much she may wish it were not so, Wheeler herself. As a result, Terra Incognita is less about Antarctica than about a strange parallel universe, where men are 'beards' and women token 'beards'.

Colonialism is dealt with as a historical phenomenon spurring earlier explorations, especially those by the British, and the way heroes were created on the ice at a time when Britain needed to compensate for its losses in other areas of the Empire is illustrated in the way the history of Scott is analysed in some detail, especially the way his story was promoted through books, films and photographs during the First World War to inspire soldiers to keep on fighting and value self-sacrifice in a greater cause. 
Tourism is hardly present as a discourse in the sense that Antarctica is practically offlimits to the normal tourist, and there is no-one living on the ice to be described, photographed, exploited or affected by visitors (except the wildlife). The book represents a kind of anti-tourism discourse, in that Wheeler has deliberately chosen a destination that is the ultimate in 'off the beaten track' originality, and with its many deliberate echoes of the early explorers, the Antarctica she constructs is seen as the last great frontier, with herself as the last in a long line of heroic individuals who 'penetrate' the wilderness, rather than as the well-cared-for guest of rich and powerful scientific bases.

One rhetorical aspect which features heavily in Terra Incognita, and is not common in other recent travel writing, is the series of transcendental epiphanies experienced by the writer: if nothing else, Wheeler at least enjoys her travels, and presents them as a positive experience in which she learns not only about a new region and its unique beauty, but also learns to appreciate her 'inner voice' which she clearly represents as a spiritual experience. She claims to be a religious believer before heading south, and what she finds there confirms her faith and provides her with much happiness. In this sense the contrast with Davidson's experiences in the desert with the Rabari could not be more marked, as is the case with other post-war travellers such as Mary Morris (1993) or Dervla Murphy (1995), who are far more attuned to the negative aspects of travel, and seem to expect sympathy from the reader for their sufferings and endorsement of the implicit message that travel has to involve pain for it to be 'authentic' - otherwise it becomes tourism.

However it is salutary to bear in mind that Wheeler is able to experience transcendental spiritual moments precisely because she is in a very privileged position: the cost and the logistics of travel in Antarctica, and the nature of the uninhabited terrain, are the very reasons why it is such heaven for the lucky individual who gets to visit. We are forced to the uncomfortable conclusion that it is, in fact, the presence of other people - of the native populations of foreign countries in particular - that make the travel experiences of so many recent writers into a kind of Calvary of suffering: they are robbed, cheated, threatened, lost, confused, stared at, unable to communicate, have to deal with strange food and customs, and are frequently forced to retreat to safe havens of First World comfort when the going gets tough. It is not Wheeler's special relationship with the Higher Powers that makes her time in Antarctica so enjoyable; it is the lack of natives and foreign culture.

As Said suspected, modern Orientalism may have taken new forms, "a personal twist", a more refined presentation of the Other arising from personal encounter rather than scientific study, but beneath the surface impression of a post-colonialist interest in other cultures, what we find repeatedly in the work of Western women travel writers in the latter part of the twentieth century is an obsession with self which has found 
ideological justification in the contemporary discourse of feminism, and less actual interest in the Other than we have seen in travel writing throughout the century.

In the desire to concentrate on the 'inner journey' and gain status and credibility by focusing on the writer's unique status as a sensitive individual, somewhere along the line the foreign country is reduced to an exotic or hostile backdrop to the drama of the personal life of the author. Changes in social experience of travel, of media access to foreign places, the enormous growth of tourism and the growing market for products aimed at a female readership have all combined to produce a style of travel writing which is unsure of its role alongside guidebooks, documentary television, journalism, and even amateur holiday videos and photographs. If tourism, one of the largest industries in the world, has blurred forever the distinction between traveller and tourist, broken down class barriers and brought the foreign into the domestic (and brought the domestic to the foreign) then the role of the travel writer as a special envoy who travels into the unknown is a threatened one. It is salutary to end with a reminder of Edward Said's prophetic analysis of the nature of modern Orientalism: "a vision of the contemporary Orient, not as narrative, but as all complexity, problematics, betrayed hope - with the White Orientalist author as its prophetic, articulate definition" (Said 1978: 239).

\section{REFERENCES.}

Bell, G. 1907. The Desert and the Sown. London: Heinemann.

Bird, I. 1982 (1879). A Lady's Life in the Rocky Mountains. London: Virago.

Chaudhuri, A. 1997. London Review of Books, Vol. 19, No. 18, September 18.

Conrad, J. 1973 (1898). Heart of Darkness. London: J.M. Dent.

David Neel, A. 1988 (1927). My Journey to Lhasa. London: Virago.

Davidson, R. 1997 (1996). Desert Places. London: Penguin.

Kobak, A. 1997. New York Times February 16.

Maillart, E. 1986 (1947). The Cruel Way. London: Virago.

Morris, M. 1993. Wall to Wall: A Woman's Travels from Beijing to Berlin. London: Flamingo.

Murphy, D.1995 (1977). Where the Indus is Young. London: Flamingo.

Said, E. 1978 (1977). Orientalism. London: Penguin.

Stark, F. 1938. Baghdad Sketches. Vermont: The Marlboro Press.

Stewart, L. 1996. Times Literary Supplement December 13. 
Walker, N. 1998. “On an Inner Journey”. Times Literary Supplement. July 31.

Wheeler, S. 1996. Terra Incognita: Travels in Antarctica. London: Vintage.

Wheeler, S. and D. Birkett. (eds.) 1998. Amazonian: The Penguin Book of New Women's Travel Writing. London: Penguin. 